\title{
Class Communication Tools in a Blended Graduate Course
}

\author{
John Kwame Boateng \\ School of Continuing and Distance Education, College of Education, University of Ghana, PO Box LG 31, \\ Legon, Accra, Ghana
}

\section{The research is financed by CODESRIA. Grant letter reference number DIAS/Res.Contr09/2015 (Sponsoring information) \\ Abstract}

The study presents a research carried out at the School of Continuing and Distance Education at the University of Ghana during the second semester of the 2015-2016 academic year. The research was carried out over a period of sixteen weeks from August to November 2015 for a course DEEL 612 taught at the graduate level. The study involved 11 graduate students who were studying for a Master's Degree delivered in a blended mode. An in-depth telephone interview of the eleven students conducted by a trained and experienced interviewer was carried out. Interviews were recorded and transcribed. Results show that, respondents studying online enjoyed equality in the ability to share thoughts and ideas. They found studying online with the use of the Sakai LMS to be useful, flexible and convenient. Respondents in the study affirmed that, Sakai LMS enhanced interactivity with peers and the instructor in ways that supported trusted relationship building. This helped learning to take place, made it of fun and innovative.

Keywords: Blended mode, online, Sakai LMS, interactivity, student learning

DOI: $10.7176 / \mathrm{JEP} / 11-13-10$

Publication date:May $31^{\text {st }} 2020$

\section{Introduction}

Effective use of technology in educational settings and its successful integration increases the productivity of instructional processes (Eristi, Kurt \& Dindar, 2012). According to Luo (2011), the advancement of educational technologies, especially computer technologies has brought significant changes in the educational systems in the higher education institutions, with computers playing more and more important roles in teaching and learning.

Advances in modern technology infrastructure, social media and modern media technologies has made possible the integration of learning management systems and other internet enabled technologies such as Skype, Facebook, twitter, adobe-connect has revolutionized ways by which student-instructor interactions during class and after class happens even in a developing country like Ghana. Combining face-to-face and online instructor learner interactions with a learning management system and prescribed set of learning activities creates the space for collaborative learning with incentive to transform learners to become professionally competent (Johnson \& Johnson, 1999).

When technology mediates interaction between instructors and learners and from learners to learners, it promotes critical thinking through shared understanding about knowledge of differences and similarities. Johnson \& Johnson, (1999), notes that, such an approach would provide good opportunities for developing social and communication skills, positive attitudes and help build social relationships. Davidson, Richardson \& Jones (2014), also observe that integrating technology and instruction will allow students to engage in collaboration, real-world authentic learning and social interactions with peers that will prepare them for a global society that relies on technology.

The use of digital technologies and online materials has generated diverse lines of research (Robinson and Hullinger, 2008). And rapidly, African universities are absorbing digital technologies. Yet in their quest to acquire new technologies, their impact and value on educational outcomes have been under-investigated. This study investigated the impacts of different instructor-student interaction formats in a blended-learning course at the School of Continuing and Distance Education, University of Ghana campus at Legon in Accra in terms of its usefulness for convenience, flexibility, as well as for collaborative and communities of engaged learning.

Lopez-Perez, Perez-Lopez, Rodriguez-Ariza \& Argente-Linares (2013) observe that, in blended learning, the Internet acts as an instrument to complement traditional forms of instruction, in the belief that the incorporation of new information and communication technologies may lead to more efficient and effective education. Darrington, Berryhill \& Swafford (2006) noted that high levels of interaction with the faculty lead to higher levels of student performance and more positive attitudes in online courses. Other scholars have made similar observations that the interaction between educators and students can be greater online than with that of the on-campus class (Gilbert \& More, 1998; Jarvela \& Hakkinen, 2002).

The above-cited studies are carried out in western, developed-country contexts. It remains unclear whether similar levels of student engagement and learning outcomes could be achieved with Ghanaian students who have traditionally been accustomed to face-to-face methods of teaching and learning, despite rapid take-up of new 
technologies in their personal lives. This study in Ghana will contribute to that knowledge gap about how out-ofclass communication between students and faculty using the Sakai learning management System can enhance flexibility, convenience and student engagement in a community of learning.

\subsection{Research Questions}

Students in a master-level humanity and Social Science course (DEEL 612: Costs and Economics of Distance Education at the University of Ghana was the study population. Eleven master degree students participated in the study.

Research questions included the following:

a. Do students look to the use of the Sakai LMS for convenience?

b. Do students look to the use of the Sakai LMS for flexibility?

c. Does the use of the LMS;

i, Make it easy for students to connect with fellow students and the instructor?

ii Translate into positive feelings about technologies for teaching and learning?

iii Allow students to take control of their course activities?

\subsection{Theoretical basis}

We begin to review literature by first examining theories about online interactions and student learning outcomes to portray the effectiveness of online learning in comparison with the traditional face-to-face interactions. We follow with a brief review of studies that examine flexibility and convenience aspects of the use of LMS for online learning and interactions. We finish off by discussing research studies that examine student attributes that are important for academic success such as making connections and sustaining them with peers and the instructor, maintaining positive feelings to promote motivation and persistence and taking control over their course activities.

Johnson, (2001), traced the roots of online communities to constructivism. Thoms \& Eryilmaz (2014), citing Hagstrom \& Wertsch (2004) states that constructivism stems from the interactions and experiences of the learner. Thoms \& Eryimaz (2014) argues that interactions and experiences of students can be directly influenced by user's engagement with course technologies. In online learning, the technologies employed become the primary tools for interaction. Thoms \& Eryimaz (2014), further shows that, at the center of any learning community is the learner and while he or she is influenced greatly by their interactions with technology and others, each may construct knowledge differently from their peers.

Piaget (1952) theorized that learning could be based on the interaction and experiences of the learner within specific context. Constructivism provides a holistic view of individual learning (Thoms \& Eryimaz, 2014). Matthews (2002) shows that constructivism begun as a theory of learning but has progressively been used as a theory of education, of the origin of ideas and of both personal and scientific knowledge. Thus engaging students adequately in their course content through effective interactions with instructors can enhance student success. Engagement theory posits that, students must be meaningfully engaged in learning activities through interaction with others (instructors and peers) facilitated and enabled by technology (Dalsgaard, 2006).

Using a sample of 1000 students, Abrantes et al. (2006), revealed that, perceived learning depends directly on student interest, pedagogical affect and student learning performance and indirectly on the student-instructor interaction, the instructor's responsiveness, course organization, the instructor's likeability, concern and the student's learning performance. According to Paswan \& Young (2002), student-instructor interaction refers to the opportunity given to students to ask questions, practice the free expression of ideas, develop their skills and improve class discussions. On this basis our three hypotheses were formulated.

\subsection{Literature Review}

2.1 Learning Management System

Caruso and kvavik (2005) find that, most students have used a LMS and most have had positive experiences. According to the researchers, LMS are used differently among different Institutions (Dias \& Diniz, 2014; Gerber and Grote, 2008). Respondents in Caruso and Kvavik (2005) study, report that an overall rate of use of LMS to be $72 \%$. Students at doctoral level were $75 \%$ more likely to have taken a course that used a LMS. Of students that have ever used LMS, 75\% reported a positive or very positive experience. Only 5\% are negative or very negative and $20 \%$ are neutral. When assessing what factors that contributed to positive experience with the use of LMS, Caruso and Kvavik (2005), find that students who agreed or strongly agreed that courses using LMS helped them to take greater control of their course activities in terms of planning and managing time, reported the most positive experience with LMS. Other factors found important were perceived skill of the instructor and that is followed by the instructor's use of LMS to provide prompt feedback.

\subsection{Flexibility in using learning technologies}

According to Majumdar (2015), learners always look for flexibility in time, space, place, content selection and 
delivery of instructions. To satisfy such requirements in earlier times was quite impossible because there was nonavailability of proper tools. Now with the advancement made in technology uses for teaching and learning, it has become feasible and possible to implement open and flexible teaching and learning strategies using ICT as tools. Flexible access to content and learning resources via network across conventional class rooms, homes and community centres has been the defining characteristic of what has come to be known as distributed learning (Majumdar, 2015; Flecher et al. 2007; Shimoni et al. 2013; Kozlowski \& Bell, 2007).

Learning anytime, anywhere with synchronous and asynchronous communication across space, time and pace is key to web based instruction according to Majumdar (2015). With the advent of online tools, it has now become reality to create content websites, online education to support and assist face-to-face instruction in an innovative way. Communicating through e-mail, searching for information, locating a proper website has become now the key to success in online learning (Majumdar, 2015). Additionally, developing online and offline

\subsection{Motivating students}

Parasuraman et al. (1985) discussed the concept of responsiveness at length and described it, as the willingness to help students by providing needed service promptly. Paswan and Young (2002) have shown that, a strong involvement of teachers in their students does stimulate students' interest in learning and for that matter their satisfaction or accomplishment in their learning. According to Hammond and Snyder (2000), teachers should have the capability to know and understand student needs and be able to respond to them promptly. The authors, (Hammond and Snyder, 2000) describes the concept of responsive teaching as having the capacity to engage in systematic learning from the teaching context and practice and from a more generalized theory of teaching.

\subsection{Connecting with Instructors and Peers}

According to Siemens (2005), connectivism recognizes that in the online learning environment, seeking and constructing knowledge is most often accomplished through interaction and dialogue. Siemens (2002) also notes that, the learner-learner interactions in an e-learning course can be viewed as a four-stage continuum of communication, collaboration, cooperation and community and proposes that in an online course interaction will probably not go beyond communication or collaboration most of the time. From Siemens (2005) perspective, learning consists of retrieving information, from self, others, and machines, collaborating to create knowledge, and applying information to current contexts. Howe \& Straus (2007) argue that undergraduate students will continue to take up informational technologies that help them meet their educational needs and goals better. (This is clear in America and other countries in the west, but it is proving true in countries across Africa, as well.) As a result, they predict that college students will seek to use more educational technologies and avoid traditional educational methods.

Meanwhile, faculty continues to use traditional educational methods, such as through weekly office hours. (Acitelli, Black \& Axelson, 2003) Thus, there can be a generational mismatch as observed by Bippus, Kearney. Plax \& Brooks (2003), find that students rarely seek help during office hours. Faculty is thus urged to explore newer communication methods (Kuh \& Hu, 2001; Li et al., 2011; Nadler \& Nadler, 2000).

(According to Li \& Pitts, (2009), innovative web-based technologies, such as e-mailing and the yahoo instant messenger used during virtual office hours (VOHs) are predicted to have a substantial ability to enhance the way in which faculty and students communicate with each other outside the classroom. In collaborative learning spaces, knowledge is shared or transmitted among learners as they work towards common learning goals for example, a shared understanding of the subject at hand or a solution to a problem (Brindley \& Walti 2009). But while studies have captured student preferences, very little especially in Ghana has been done to determine perceptions on why and how students use technology for its convenience, flexibility, and for communication and control.

Gibson, Boston \& Becher, (2011) explained the concept of social presence in online learning as consisting of three indicators namely; 1 . Affective expression, where learners share personal expressions of emotion, feelings, beliefs, and values in their online course; 2. Open communication, where learners build and sustain a sense of group commitment in their online course and 3. Group cohesion, where learners interact around common intellectual activities and tasks in their online course. Shea \& Bidjerano (2014) observe that, American postsecondary students who studied online or at a distance for some of their courses significantly demonstrated better chance of attaining a community College credential than do their classroom only counterparts. The question is, did the use of the online medium of study allowed those students studying at a distance to take more control of their course activities because of the flexibility, the convenience and more effective ways to communicate and interact with the instructor and that made them outperform their counterparts who did not use the online medium to study?

\subsection{Methodology}

3.1. Scope and characteristics of the sample

The Cost and Economics of Distance Education and E-Learning course examined the highly competitive global business environment for distance education and training. Topics included the supply and demand of education 
services in emerging and existing markets, the competitive positioning of organizations and increasing reliance on collaborations. Emphasis was placed on skills distance education managers need in planning and developing costeffective programmes, products and services that are targeted to specific markets.

The course was taught to eleven graduate students in a Master's Programme delivered through a blended learning approach. The course was taught in one semester during a sixteen week period. The teaching method employed a combination of face-to-face classes and series of online interaction with the instructor. Students' met the instructor face-to-face over an eight hour period spread over two Saturdays (in the beginning and the end of the sixteen week duration). The instructor and students interacted face-to-face four hours on each of the two Saturdays. The rest of the period was devoted to online interactions and activities. This was a three credit course pre-recorded video lectures, Power Point presentations, lecture notes and reading materials and others were made available online using the Sakai Learning Management System.

All recorded lectures and other resources making the course content were available for viewing from the start of the Semester until the specified expiration date. After the expiration, lectures, content, materials, quizzes and other resources were made unavailable. Students completed online activities by logging into Sakai. Activities planned for students in the online sessions were calculated to help achieve greater understanding of the content, concepts and reinforce procedures. The course website contained two kinds of activities, first individual oriented activities that were to promote understanding of the content and concepts. Secondly, participatory and collaborative activities such as forum meant to help students interact, discuss and debate issues and thus help them understand concept taught better.

The instructor coordinated the online activities and interactions providing useful feedbacks. The use of group oriented activities empowered students to get involved more in the learning process with the belief that this would impart positively on their learning outcomes. The instructor explained the different activities on the website as they corresponded to the content presented in the course outline. Students were taught and trained on how to access the course content using the individual oriented (access course content, quizzes, etc.) as well as the group oriented (forum, chats) tools for true empowerment.

\subsection{Research Participants}

The criterion sampling method was employed to select participants for this study. The criterion used was that participants must be a graduate student that was enrolled in the course Costs and Economics of Distance Education and E-learning (DEEL 612). As per the criterion determined, 11 graduate students were enrolled in the course for the Second Semester of 2015-2016 academic year.

\subsection{Gathering the Data}

Research data were gathered through in-depth interviews with the 11 research participants. All eleven participants were interviewed and an in-depth data collected through telephone. Interviews were recorded and transcribed. The telephone interview, were conducted by a trained and experienced interviewer.

\subsection{Data Analysis}

For the analysis of data collected through the in-depth interview, responses from research participants were recorded and transcribed. The transcribed data were examined in-depth.

Thematic analysis was 'made to include such phrases that constituted themes of interest for analysis, data analysis per the major themes and sub-themes and the subsequent interpretation of the findings obtained. Collected data were first described, interpreted and findings obtained are discussed.

\subsection{Results}

4.1. Demographics of research participants

Shown in the Table 1 below, respondent's demographic characteristics have been grouped into gender, student status, employment status and residential status. Shown in this table, it is indicated that males contributed to $81.8 \%$ of the study respondents whiles the rest of $18.2 \%$ were females. All the study respondents were identified as part time students. According to the respondent's employment statuses, it is shown that majority of the respondents consisting of 90.9 percent were employed whereas $9.1 \%$ of them were unemployed. All the respondents in this study have shown that they not resident on campus. 
Table 1: Information describing respondents

\begin{tabular}{lll}
\hline Respondent & Frequency & Percent \\
\hline Gender & & \\
Male & 9 & 81.8 \\
Female & 2 & 18.2 \\
Student type & & - \\
Full Time & - & 100.0 \\
Part Time & 11 & 90.9 \\
Employment & & 9.1 \\
Employed & 10 & - \\
Unemployed & 1 & 100.0 \\
Residence & & \\
On-campus & - & 11 \\
Off-campus & 11 & \\
\hline
\end{tabular}

The in-depth interviews focused on the three research questions and hypothesis formulated for the study.

Table 2 presents the major themes and sub-themes regarding the three hypotheses formulated.

Table 2. Scope and themes of in-depth interviews

\begin{tabular}{|l|l|l|}
\hline Hypothesis & Major Theme & Sub-themes \\
\hline $\begin{array}{l}\text { Research question 1. Do } \\
\text { students look to the use of the } \\
\text { Sakai LMS for convenience? }\end{array}$ & Positive perceptions & $\begin{array}{l}\text { 1. Convenience } \\
\text { 2. Easy to use }\end{array}$ \\
\hline $\begin{array}{l}\text { Research question 2. Do } \\
\text { students look to the use of the } \\
\text { Sakai LMS for flexibility? }\end{array}$ & Distributed learning & $\begin{array}{r}\text { Reach across: } \\
\text { 1. Space, time and space }\end{array}$ \\
& $\begin{array}{l}\text { 2. With Sakai LMS chat, forums, } \\
\text { announcements }\end{array}$ \\
$\begin{array}{l}\text { Research question 3. Does the } \\
\text { use of the Sakai LMS facilitate } \\
\text { easy connection, generate } \\
\text { positive feelings and allow } \\
\text { students to take control of their } \\
\text { course activities }\end{array}$ & $\begin{array}{l}\text { Communication } \\
\text { 1. } \begin{array}{l}\text { participate in online discussions } \\
\text { opportunity to ask questions and get }\end{array}\end{array}$ \\
\hline
\end{tabular}

4. 1.1 Advantages of online communication

A number of obvious advantages have been associated with online communication for education purposes. Students studying online enjoy equality in the ability to share thoughts and ideas, far from the scenarios where the students occupying the front roll of seats or those with loudest voice get heard. In this study, respondents' perceptions informed and affirmed their experience of interactions with the instructor and peers and their perceived cognitive, psychomotor and affective learning. On meaningful learning, one student had this to say:

"I prefer studying online to face-to-face. Is flexible, I can work or study at my own convenience, at my own pace wherever I am it doesn't matter the location, unlike the face-to-face where one is restricted to a particular place" Another respondent had this to say:

"I will like to do everything online. If I am working online and face some difficulties or challenges, I can pause and leave a message or note to the instructor or colleague students about my study challenges and I get feedback pretty soon"

A respondent learning from a distant location had this to say:

"Because of the distance, I didn't prefer the face-to-face. My problem was the distance, but face-to-face is good, because you get much explanation, and because I preferred the online there were a lot of things I didn't understand but have to read on my own"

Another respondent nailed the point about meaningful learning from online sources. He said:

"Online is preferred because, you are able to learn from online at your own pace. For example, me as a worker, I benefit from using technology to learn. Sometimes I have to come for lectures and I am caught up with many things to do, and it dawns on me that, I can just remain in the house and yet learn with the online. The stress of coming for the face-to-face interaction is massive compared to the flexibility and freedom that comes with online learning."

A respondent made contribution as follows:

"I think things are changing, the time to go for face-to-face and discussion in person is not there any longer. We realize that now people are doing multiple jobs. It is better for people to appreciate the online form of learning to better combine jobs, family and education. To me the online was beneficial a lot than the face-to-face. People should be educated on the use of the online platform so that they can enjoy the benefits of the online learning 
management systems".

The instructor's physical or online presence was a determining factor for a meaningful learning to happen. This is affirmed with this contribution from a respondent:

"Studying online is made convenient, because you can communicate with the instructor everywhere, for example me, am at the rural area but am able to learn through online. If there is any assignment, I am able to do it and have a feedback. If I have a question, I can ask through this medium"

Another respondent had this to say regarding the instructor's online presence, flexibility that the Sakai LMS offers and how convenient for students:

"Before, I started the Master's Programme in e-learning, I had never used any online platform to study. The use of the University of Ghana learning management system (UG LMS) exposed me to the usage of online teaching and learning management. In my class, we are all scattered in around Accra and some in Kumasi and Volta Region, but on the platform, everyone is brought on board. The instructor provides prompt feedback. If a lecturer gives assignments, he marks and gives comments about how questions were answered. I don't need to come and see the lecturer to check my grade or my scores, in fact the UG LMS has come to help us. We are covered in time, space and pace indeed!"

4.1.2 Collaborations in learning

The study found that, the instructor's online presence to interact with respondents' helped to build connections with students. Students by interacting with their peers build connections with them as well and became a community engaged in learning together. The respondents, it appears came to depend on these connections and trusted the instructor and their peers to remain professionally engaged with them during the duration of the course and beyond. This finding is deduced from the contribution from a respondent:

"I opt for office hours online, because you can trust the instructor to get back to you, even if he misses the appointment time and most often really soon. With the face-to-face office hours, something might happen and he cannot be available to meet you and you lose him for another good week or more time. But with the online, you can send him a mail or message through the medium and instantly he can reply with helpful information. To me, the online is faster than the face-to-face. It is very convenient. I have come to rely on it and trusted that the instructor will be there for me no matter what"

Another respondent had this to say regarding a situation where interaction between instructor and student resulted in connection building:

"And it is interesting, when you come to think of the kind of academic relationship that begins to develop between the instructor and us students. Online makes learning much of fun and innovative"

Fundamental to Sakai's role in the promotion of effective student-to-student as well as student-to-instructor interactions to facilitate connection building are some inherent competences that are intended to be developed through the use of Sakai and the relationship with assessment strategies employed by Sakai. Respondents identified critical thinking, communication, creativity, collaborative learning and computational thinking skills as useful competencies that students who are exposed to the Sakai LMS could build to improve their knowledge, skills and attitudes. On helping students who learn with Sakai building critical thinking skills, a respondent had this to say: "The use of Sakai as the LMS made possible the formation of small and large groups in ways that encouraged us students to build communities through which we argue, think, pair and share ideas"

Another participant had this to say:

"The interactive features, like the forum, gives opportunity to see others' views and appreciate different ways of dealing with a problem. Once you argue out issues of concern, you may agree to disagree or have varied solutions to the same problem which means that everyone goes home better than he was before the interactions"

Another had this to say:

"The Sakai community feedback options increased student participation rates by providing flexible access to participate whenever and wherever convenient"

4.1.3. Sakai

On Sakai's usefulness in imparting computational thinking skill among students who use the LMS for online studies, a student had this to say:

"Computational thinking involves solving problems, designing systems and understanding human behavior. The Sakai LMS empowers learners to think computationally"

Another student had this to say:

"Sakai is wonderful, it is easy to navigate, you don't need a lot of training, you don't need a lot of help, and you can easily use Sakai without much assistance, very, very easy to use. It allowed me to learn online, downloaded course resources and continue to learn offline when connectivity was lost"

A further usefulness of the Sakai LMS is the opportunity for meaningful discussion among classmates. The responsibility for the quality of discussion was the domain of the instructor. Respondents in the study described successful facilitation of interaction by the instructor in a way that made students feel like they belonged to a community of engaged learners. 


\subsubsection{Positive feelings}

The positive feeling with the Sakai platform and the learning experiences enjoyed by the community of learners means that instructors as well as students promote this type of interaction by ensuring that their communication is consistent and clear showing that the community members care for each other and are happy to assist. A respondent made the following observation:

"In our class, two groups were formed to execute group assignments. To me what made the groups successful in their respective tasks were the ability to communicate verbally and writing, the ability to solve problems, work effectively with one another, manage time and responsibilities effectively to execute the group assignments"

On creativity in the use of Sakai to change the way students learn, a respondent has this to say.

"Creativity does not appear by chance. We as students must make conscious efforts. We need to practice, and practice and practice Sakai more often to understand all about its usefulness so as to become more creative in the way we use it to transform the way we learn"

Another had this to say:

"Based on the usage, it was flexible, you don't need so much skills, the moment you can understand the necessary icons, and you won't have a problem"

\subsection{Discussion}

\subsubsection{Online interactions}

Online interactions were beneficial when students could achieve the flexibility and convenience they needed for effective learning to happen. When they work at their own convenience, at their own pace, wherever and whenever they want. The online presence of the instructor, to communicate and demonstrate mastery of the subject matter and content in the provision of prompt feedback to students determined whether or not students perceived the interaction as positive, meaningful and beneficial. Additionally, the extent to which the online experience promoted student-to-student interactions, as well as the student-to-instructor interactions helped the student develop a clear sense of self in directing their learning.

Above findings of this study resonates with other investigations about the role of interaction in online learning. The observation that, respondents in the study found the use of the Sakai LMS to be flexible and convenient in a way that helped to maximize interaction with fellow students and instructor for learning resonates with the fundamentals of constructivism which holds that, learning occurs when there is interaction with the environment including social interactions with others (Von Glaserfeld, 1996, page 4).

Piaget (1977), noted that interaction needs to be such that it encourages a person to accommodate or assimilate new and even contradictory information into his or her cognitive view. Vygotsky (1986), maintained that, students need interaction with more knowledgeable others and peers in order for higher-order learning to occur. Our study has confirmed this assertion. Cobb (1996) argued that social constructivism brings about cognitive development through social activity. In our study, we find that when students' engaged their peers in academic discussions or shared materials and ideas related to the course using the Sakai LMS, it enhanced their learning.

Findings from this study support the argument that the lack of human interaction in online courses impacted negatively on learning outcomes for students (Stoll, 1999). However, our findings moved against Stoll's position that online education lack human interaction. Our respondents have spoken about online community of learners and content champion (the instructor) with whom they have built a thriving professional relationship or connection online through the interactions that have ensued among them and they have found such interactions engaging and trusted.

4.2.2 Sakai Promoted Collaborative Learning

Lai (2011) maintained that, research on collaborative learning has developed within three distinct dimensions: research comparing group performance to individual performance; research identifying the conditions under which collaborative learning is more or less effective and research investigating the characteristics of interactions that mediate the impact of collaboration on learning, including use of new technologies that facilitate asynchronous text-based interactions.

Our study fits more into the third dimension and has suggested that collaborative learning through the use of the Sakai LMS is characterized by shared goals, a high degree of negotiation, interactivity and interdependence. Our study have shown that, interactions producing clear explanations through feedback provision in series of back and forth interactions are particularly valuable for improving student learning, especially for the student being provided the clear explanations. It became clear in our study that, nonresponsive feedback on the other hand did not perhaps contribute to useful learning in the Sakai LMS.

A number of factors may moderate the impact of collaboration on student learning (Lai, 2011). These include, student characteristics, group composition and task characteristics. For instance, Lai (2011) observe that, patterns of interaction as well as the effects on subsequent performance vary across males and females, with boys participating more actively and appearing to benefit more from collaborative learning than girls. Similarly, it appears that, high ability students may participate more actively than low-ability students. Thus group composition 
with respect to gender and ability appears to be an important factor in collaborative learning. Our study, with the Sakai LMS has not looked at these important areas and they remain fertile grounds for future studies to explore.

\subsection{Conclusion}

This study examined how eleven Master degree students from the School of Continuing and Distance Education, University of Ghana perceived online interactions in their course with the instructor through the use of the Sakai LMS. It has been revealed in the study that, the instructor's physical or online presence was a determining factor for an effective student-instructor interaction, feedback provision and learning to happen. In addition to promoting effective student-to-student as well as student-to-instructor interactions for effective learning to happen, respondents' identified critical thinking, communication, creativity, collaborative learning and computational thinking skills as useful competencies that students who are exposed to the Sakai LMS could build to improve their knowledge, skills and attitudes.

Furthermore, skills in mastering the use of the Sakai LMS, metacognitive competences related to the students' capacity to reflect upon his or her learning processes with the ability to assess deficiencies in knowledge, and avoid wrong turns in learning as well as the ability to collaborate with others in learning are some of the ways in which the use of Sakai LMS empowered respondents' to learn differently. The findings are important as they provide insight into how the use of the Sakai LMS can better be implemented in a university system.

Nevertheless, this study did have some limitations that must be shared. The generalizability of our findings is challenged by the fact of our rather small sample size of eleven. Future studies should address this issue of sample size with multiple research methods, including quantitative methods with a much larger sample size. Our study only interviewed students. Future studies must include perspectives from instructors as well.

In conclusion, it is observed that, employing technology, the Sakai LMS for teaching and learning can have significant ripple effects in higher education. In the coming years, such technologies will put education within the reach of many more individuals in Ghana and around the world, and will allow greater specialization in curriculum and teaching methodologies than ever before. However, with these advantages comes the challenge of ensuring that university infrastructure and operations are in place to support the adoption of technology on university campuses in Ghana and elsewhere.

Also faculty using technology to teach must be provided with the required resources and processes improvements. They must also be rewarded and remunerated attractively to ensure their sustained motivation and continued provision of feedback to maintain effective teaching and learning. Moreover, administrators will need to weigh carefully how budget funds are spent, decide what technologies present the most promise, and determine how best to support these technological advances while avoiding the risk of failure. Universities in Ghana and for that matter Africa must consider how to make the most of using technology to teach and learn, including the use of learning management system opportunities to ensure that they remain competitive in the global marketplace in education.

\subsection{References}

Abrantes J.L., Saabra, C., Lages, L.F. (2007). Pedagogical affect, student interest and learning performance. Journal of Business Research. Science Direct. Elsevier. Vol 60, Issue 1, pp. 960-964.

Acitelli, L. Black, B., \& Axelson, E (2003). Learning and teaching during office hours. Center for Research on Learning and Teaching, University of Michigan, Retrieved of February 5, 2005 from: http://www.crlt.umich.edu/gsis/p4.5.php1

Bauk, S. I. (2015). Assessing Students' Perception of E-Learning in Blended Environment: An Experimental Study. Procedia - Social and Behavioral Sciences, 191, 323-329. http://doi.org/10.1016/j.sbspro.2015.04.393

Bippus, A., Kearney, P., Plax, T., \& Brooks, C. (2008). Teacher access and mentoring abilities: Predicting the outcome value of extra class communication. Journal of Applied Communication Research, 3 (1), 260-275.

Brindley, J. E., Walti, C., \& Blaschke, L. M. (2009). Creating Effective Collaborative Learning Groups in an Online Environment. The International Review of Research in Open and Distance Learning, 10(3). Retrieved on January 24 from http://www.irrodl.org/index.php

Butler-Kisber, L. (2013). Teaching and learning in the digital world: Possibilities and challenges. Learning landscapes, Spring 2013, Vol 6, Issue 2, 424pp.

Caruso, J. B \& Kvavik, R.B., (2005). "Students and Information Technology 2005: Convenience, Connection, Control and Learning". Presentation of the Results of an EDUCAUSE Center for Applied Research Survey, May 22, ECAR key findings. Retrieved on January 24, 2017 from: file://Users/drjohnkboateng/Desktop/ICT\%20use\%20for\%20convenience\%20and\%20control.pdf

Cobb, P. \& Yackel, E., (1996). Constructivist, Emergent and Sociocultural Perspectives in the Context of Developmental Research, Educational Psychologist, Vol 31, Issue 3/4, pp. 175-190.

Cobb, T. (1997). Cognitive efficiency: Toward a revised theory of media, ETR\&D, Vol 45, Issue 4, pp. 21-35

Dalsgaard, C. (2006). Social software: E-learning beyond learning management systems. Retrieved from 
http://www.eurodl.org/materials/contrib/2006/Christian_Dalsgaard.htm on 28/12/16.

Davidson, L. Y. J; Richardson, M. \& Jones, D. (2014). Teachers Perspective on Using Technology as in Instructional Tool. Research in Higher Education Journal, Vol 24, pp. 1-25

Darlington, V.A., Berryhill, A \&Swafford, J. (2006). Strategies for enhancing student interactivity in an online environment. College Teaching, 54 (1), 190-193

Dias, S. B., \& Diniz, J. A. (2014). Towards an enhanced learning management system for blended learning in higher education incorporating distinct learners' profiles. Educational Technology \& Society, 17, 307-319

Edwards, J.T., \& Helvie-Mason, L. (2010). Technology and Instructional Communication: Student usage and perceptions of virtual office hours. MERLOT Journal of Online Learning and Teaching, vol 6, No. 1.

Eristi, S.D, Kurt, A.A. \& Dindar, M. (2012) Teachers' Views about Effective Use of Technology in Classrooms. Turkish Online Journal of Qualitative Inquiry, Vol 3, Issue 2, pp 30-41.

Fletcher, J.D., Tobias, S., \& Wisher, R. ( 2007). Learning anytime, anywhere: Advanced distributed learning and the changing face of education. Educational Research, 36(2), 96-102.

Gerber, M., Grundt, S., \& Grote, G. (2008). Distributed collaboration activities in a blended learning scenario and the effects on learning performance. Journal of Computer Assisted learning, 24(3), 232-244.

Gilbert, L., \& Moore, D. R. (1998). Building interactivity into web courses: Tools for social and instructional interaction. Educational Technology, 38 (3), 29-35

Hammond L.F., Snyder J. (2000). Authentic assessment of teaching in context. Teach Teach Education, Vol 16, Issue 1, pp 523-545.

Howe, N., \& Strauss, W., (2007). Millennials go to college (2nd ed.), Great Falls, VA LifeCourse Associates.

Huba, M. E., \& Freed, J. E. (2000). Learner-centered assessment on college campuses: Shifting the focus from teaching to learning. Boston: Allyn and Bacon.

Jarvela, S., \& Hakkinen, P., (2002). Web-based cases in teaching and learning: The quality of discussions and a stage of perspective taking in asynchronous communication. Interactive Learning Environments, 10 (1), 122.

Johnson, C. (2001). A survey of current research in online communities of practice. Internet and Higher Education, Vol 4, Issue 1, pp 45-60

Johnson, D. W., \& Johnson, R. (1999). Learning together and alone: Cooperative, competitive, and individualistic learning (5th Ed.). Boston: Allyn \& Bacon. MA

Johnson, K.A. (2011). The effect of Twitter posts on students' perceptions of instructor credibility. Learning, Media and Technology, Vol 36, Issue 1, pp 21-38

Kozlowski, S. W., \& Bell, B. S. (2007). A theory-based approach for designing distributed learning systems. In Fiore, Stephen M. (Ed); Salas, Eduardo (Ed). (2007). Toward a science of distributed learning, (pp. 15-39). Washington, DC, US: American Psychological Association, xi, 284 pp.http://dx.doi.org/10.1037/11582-002

Kuh, G. \& Hu, S. (2001). The effects of student-faculty interaction in the 1990s', Communication Education, Vol 24, Issue 1, pp. 41-47.

Kuh, G., \& Hu, S. (2001). The effects of student faculty interaction in the 1990s. The Review of Higher Education, 24 (3) 309-332.

Lai, E.R., (2011). Collaboration: A literature Review. Research Report, Pearson.

Li, L., Finley, J, Pitts, J., Guo, R. (2011). Which is a better choice for student-faculty interaction: synchronous or asynchronous communication? Journal of Technology Research, Vol. 2, Sept. 2011. http://www.aabri.com/manuscripts/10682.pdf.

Luo, H. (2011). Qualitative Research on Educational Technology: Philosophies, Methods and Challenges. Macrothink Institute, International bg Journal of Education, Vol 3, Issue 2: E13, pp. 1-16.

Majumdar, S. (2015). Emerging trends in ICT for education \& training. Gen. Asia Pacific Reg. IVETA.

Matthews, M. (2002). Constructivism and Science Education: A further appraisal. Journal of Science Education and Technology, Vol. 11, Issue 2, pp.

Nadler, M.K., \& Nadler, L.B. (2000). Out of class communications between faculty and students: A faculty perspective. Communication Studies, 51 (2) 176-188.

Parasuraman, A., Zeithaml, V.A., Berry, L.L., (1985). A conceptual model of service quality and its implication for future research. J Mark=, Vol. 49, Issue 1, pp. 41-50.

Paswan, K. A., Young J. A., (2002). Student evaluation of instructor: A nomological investigation using structural equation modeling. J Mark Education, Vol. 22, Issue 2, pp. 147-154

Piaget, J. (1952). The origins of intelligence in children. New York, NY, International University Press.

Piaget, J. (1977). Epistemology and psychology of functions. Dordrecht, Netherlands: D Reidel Publishing Company.

Robinson, C., \& Hullinger, H. (2008). New benchmarks in higher education: Student engagement in online learning. Journal of Education for Business, 84, 101-109. doi:10.3200/JOEB.84.2.101-109

Shea, P. \& Bidjerano, T. (2014). Does online learning impede degree completion? A national study of community 
college students. Computers and Education, Vol. 75, Issue 1, pp. 103-111

Shimoni R., Barrington G., Wilde R., Henwood S. (2013). Addressing the needs of

diverse distributed students. International Review of Research in Open and Distance Learning, 14, 134-157

Siemens, G. (2005). Connectivism: Learning theory for the digital age. International Journal of Instructional Technology and Distance Learning. Vol 2. No. 1, Retrieved Jan 24, 2017 from: http://www.itdl.org/Journal/Jan_05/index.htm

Siemens, G. (2002). Interaction. E-learning Course. October 8, 2002. Retrieved on January 24, 2017 from: http://www.elearnspace.org/Articles/Interaction.htm

Stoll, L (1999). Realizing our potential: Building capacity for lasting improvement. School Effectiveness and School Improvement, Vol 10, Issue 4, pp. 503-532.

Thoms, B., \& Eryilmaz, E. (2014). How media choice affects learner interactions in distance learning classes. Computers and Education, Vol 75, Issue 1, pp. 112-126. Doi: 10.1016/j.compedu.2014.02.002.

Vygotsky, L.S. (1986). Thought and language (A. Kozulin, Trans). Cambridge, M.A. MIT Press. Original work published in 1934. 